\title{
El gaucho pop(ular)
}

Reseña de Adamovsky, Ezequiel (2019). El gaucho indómito. De Martín Fierro a Perón, el emblema imposible de una nación desgarrada. Buenos Aires: Siglo XXI, 261 págs.

\author{
Diego Labra \\ diegolabraunlp@yahoo.com.ar \\ Instituto de Investigaciones en Humanidades y \\ Ciencias Sociales (UNLP - CONICET). Facultad de \\ Humanidades y Ciencias de la Educación. Universidad \\ Nacional de La Plata, Argentina
}

Cita sugerida: Labra, D. (2021). El gaucho pop(ular) [Revisión del libro El gaucho indómito. De Martín Fierro a Perón, el emblema imposible de una nación desgarrada por E. Adamovsky].

Sociohistórica, 48, e151. https://doi.org/10.24215/18521606e151

¿Cómo puede ser que desde hace más de cien años "el emblema central de la argentinidad" sea el gaucho Martin Fierro, forajido que descree de la ley y atenta con su empecinada existencia al progreso de la nación? (p. 12). Esta es la interpelación que espolea a El gaucho indómito. De Martín Fierro a Perón, el emblema imposible de una nación desgarrada, ganador del Premio Iberoamericano Book Award 2020 otorgado por la Latin American Studies Association (LASA), y nuevo libro del historiador e investigador del CONICET Ezequiel Adamovsky.

Lo profundo que penetra esta engañosamente intuitiva pregunta, y aún más, la amplitud de lecturas, recursos y fuentes desplegadas en el intento por responderla, delatan a este como un ensayo que sólo podía ser 
escrito por un autor con la madurez y la "espalda" de Adamovsky. Ya el corte cronológico posee una ambición vedada a tesistas doctorales, pues abarca no sólo los sesenta años en los que el fenómeno del "criollismo popular" tuvo "mayor pregnancia", desde la "Ida” de Fierro en 1872 hasta el nacimiento del primer peronismo (p. 14), sino que también se sumerge en los albores del siglo XIX en busca de las raíces de la poesía gauchesca. En este sentido, resulta interesante poner el libro en serie con sus dos grandes investigaciones históricas anteriores: sus historias de la clase media y de las clases populares argentinas. En relación con ellas podría aparecer como un volantazo hacia la historia cultural, pero también proponerse como una profundización en el camino ya emprendido, un seguir cavando para salir del otro lado, en los símbolos y prácticas culturales que definen esa misma historia de clases argentina.

Si la serie historia, cultura y clase evoca en el lector el espíritu de la historiografía producida por el marxismo cultural de los sesenta, el cual habita El gaucho indómito como una inspiración innombrada, puedo decir con agrado que ese entusiasmo no será defraudado. De hecho, mucha de la riqueza del trabajo obedece a que Adamovsky abrazó la tan mentada, pero pocas veces emulada, heterodoxia que caracterizó a esos historiadores del siglo pasado. Esa vocación abre una paleta de fuentes que sorprende por su amplitud, desde lo impreso a lo audiovisual, del relato oral a la propaganda política. Una predisposición para lidiar con objetos de la cultura masiva que (aún) suelen caer por fuera del interés de la historiografía, respaldada por una solvencia heurística acorde.

En el dibujo del índice encontramos, entre una breve "Introducción” y una jugosa conclusión subtitulada "La voz plebeya y el emblema de una nación desgarrada", una investigación que zigzaguea entre la reconstrucción historiográfica, el análisis sociohistórico, la historia de la historiografía y ejercicios de microhistoria y biografía. Que alternativamente pone el eje en lo político e ideológico, la clase, lo étnico y, con menor énfasis, el género (y delata, para el ojo entrenado, el origen de algunos capítulos como artículos y ponencias sometidos al rigor de los pares).

Los dos primeros capítulos, "De la gauchesca a Juan Moreira" y "La explosión del criollismo popular", presentan un pantallazo del período recortado, reponiendo el estado del arte y, como hemos subrayado arriba, expandiéndolo con nuevas fuentes. Los dos siguientes, "El gaucho visto desde arriba" y "Criollismo, experiencia popular y política" funcionan como opuestos complementarios pues profundizan el análisis en dos direcciones. El tercer capítulo lo hace "por arriba”, poniendo el foco en las disputas de las élites y dentro del Estado, mientras el cuarto lo hace "por abajo", rastreando el cruce entre experiencias cotidianas y expresiones políticas de los sectores populares en torno al fenómeno. El quinto, “¿De qué color es un gaucho? El criollismo y el perfil racial de la nación”, corta trasversalmente a los dos anteriores, reparando en las disputas por el perfil étnico de la nación. Entre los capítulos 4 y 5 encontramos también esbozadas algunas reflexiones desde una mirada de género.

"Martín Castro, un payador criollo" representa un "alto" en el libro, ya que desplaza "la lente de lo general al caso particular" del músico (p. 115), con el fin de analizar las dimensiones antes presentadas en la vida de una persona concreta. También se percibe un cambio en el registro metodológico, que da a entender de manera implícita el uso de fuentes orales. El séptimo capítulo, "El criollismo y la revisión de la historia", trae otro cambio de ritmo en la forma de una contextualización y análisis de la historiografía revisionista de los años treinta. $\mathrm{O}$, mejor dicho, en torno a la pregunta de si el criollismo popular pudo funcionar como tácita fuente de inspiración de dicha producción, al conservar viva una memoria vedada en la historia oficial de actos públicos y manuales escolares.

Los dos últimos capítulos, "El peronismo y los usos del criollismo" y "Buenaventura Luna: del criollismo al peronismo en una experiencia de vida", retoman el recorrido cronológico y argumentan la importancia que revistió el criollismo dentro del aparato discursivo y simbólico del primer peronismo: en el octavo capítulo, de manera general, y en el noveno, nuevamente a partir del registro biográfico. En ambos casos, en servicio de sostener que esta asociación simbólico-política no tuvo una "circulación unidireccional" desde arriba hacia abajo, sino que también fue "aportado al nuevo movimiento desde las bases" (p. 153). 
A lo largo de estos nueve capítulos y las conclusiones, que contiene la mayoría de la carga teórica del ensayo, Adamovsky busca sostener tres grandes hipótesis. La primera de ellas, que el criollismo popular como fenómeno cultural fue relevante hasta bien entrados los cuarenta (p. 14), se recorta en contraste con una obra con la cual El gaucho indómito dialoga de manera implícita: El discurso criollista en la formación de la Argentina moderna de Adolfo Prieto. En aquel influyente estudio, publicado en 1988, Prieto instaló una cronología que databa el final definitivo del criollismo popular en los veinte. El historiador desbanca esta periodización al expandir el concepto, el cual tomó de Prieto, para que incluya, además de objetos impreso, productos de la industria cultural como películas, grabaciones de música folclórica e historietas, como también la sociabilidad de carnavales y centros criollos.

La segunda hipótesis le da el título al libro y reza que la imposibilidad del gaucho como emblema nacional debe entenderse como síntoma de los conflictos que caracterizaron la "etnogénesis" de la Argentina (p. 212). Aquí también Adamovsky retoma puntos básicos presentes en Prieto (la lectura del criollismo "por arriba" como intento de las élites por afirmar su propia legitimidad, "por abajo" como forma sustitutiva de rebelión contra la acelerada transición de lo rural a lo urbano), pero los complejiza a través del prisma de los últimos treinta años de desarrollo de los estudios sobre la cultura popular en la Argentina. El "criollismo popular" (y ya no "populista", como usó alternativamente Prieto) deja de ser un "fenómeno cultural pasajero", "propio de las tensiones de la modernización de fines del siglo XIX" (p. 211 y 212), para ser expresión "del proceso por el cual los habitantes que se hallaron viviendo juntos en este territorio, de orígenes y condiciones enormemente diversos, intentaron construir un sentido de distintividad grupal, el sentido de un nosotros" (p. 212).

En este respecto, es notable su lectura del gaucho como una figura lo suficientemente ambigua e inclusiva que permitió dirimir tensiones presentes en la sociedad argentina de entresiglos, sin llegar nunca a romperse. En lo étnico, con un ancho de banda que iba desde el criollo que encarnaba el espíritu hispánico a un mestizo amigo de los indios. En la figura cómica de "Cocoliche", el autor encuentra argumentos para proponer los relatos criollistas también como un espacio de tránsito hacia la integración de los inmigrantes que componían la mitad de la población en la ciudad de Buenos Aires; dejando afuera, eso sí, a las mujeres, excluidas de discursos que celebraban y reforzaban modelos de masculinidad tradicionales.

Pero, más que nada, ese gaucho alternativamente "sabio manso o matrero brutal, lobo solitario o camarada de montoneras, prenda de unidad nacionalista o ícono de la protesta social", "signo cultural" imposible de "apropiárselo del todo ni estabilizar sus contenidos" (p. 191), expresó "una visión del nosotros argentino que entraba en colisión con la que proponían las élites intelectuales (en particular porteñas) y el Estado” (p. 213). Dicho de otra manera, Adamovsky lee que las élites argentinas "hayan tenido que abrazar tardíamente" al gaucho, y que "hayan fracasado en sus intentos de 'pasteurizarlo", como evidencia de una resistencia exitosa por parte de "las clases populares", pero "también y fundamentalmente, [de] la imposibilidad de construir mitos de unificación nacional que sirvieran para reforzar jerarquías sociales [...] o al menos para olvidar las diferencias" (p. 214).

De allí se desprende la tercera y última hipótesis, probablemente la más ambiciosa de todas ellas: que el éxito de esta resistencia se debe a lo que el autor conceptualiza como la "efectividad cultural de las clases populares" (p. 191). Como se describió arriba, y explicita el mismo Adamovsky en las conclusiones, esta afirmación está arraigada en los estudios culturales latinoamericanos contemporáneos, en la línea de un Alejandro Grimson o un Pablo Semán. En ese marco teórico, lo "popular”, concepto manoseado y resbaladizo si los hay, se esgrime mayormente como sinónimo de "lo subalterno"; es decir, se define de manera relacional, por su posición subalterna a las élites. Bajo ese concepto se atribuye a "las clases bajas" la capacidad de condicionar el desarrollo del criollismo, "sus contenidos y sus usos de modos diversos, directa o indirectamente", incluso "en aquellos productos generados por letrados o por el mercado", para producir un "fenómeno de la cultura" que resulta "incomprensible sin tomar en cuenta el aporte del universo popular" (p. 193). Esta hipótesis demanda demostrar, una y otra vez, las credenciales populares de los productos culturales en los cuales el criollismo se concretó. Una tarea compleja ya que, por definición, y como la génesis de la poesía 
gauchesca como fue interpretada por Ludmer y citada por Adamovsky explicita, al momento de entrar en contacto con lo letrado, con la industria cultural que los produjo, esta cultura deja de ser, en sentido estricto, popular.

En el libro, "lo popular" del criollismo se fundamenta destacando alternativamente que fue creado "por artistas o escritores de origen popular" o que fue producido "con intención de llegar a un público de clases bajas", circulando "de manera masiva sin depender de impulsos estatales" (p. 13). Para lo primero, Adamovsky recurre a biografías y anecdotarios que buscan ilustrar diferentes tipos de roce de los productores del criollismo, en su mayoría consumados profesionales y grandes jugadores de una industria cultural en ciernes, con un "mundo popular" que, a veces, usaron como inspiración, y del cual, en algunos casos, provenían. En este esfuerzo, la investigación recuerda, para bien y para mal, a los pioneros estudios de Aníbal Ford, Eduardo Romano y Jorge Rivera, quienes vieron en "mediadores" como estos un camino por el cual la cultura popular podía hacer uso (político) de la amplitud de llegada de la cultura masiva. La reconstrucción de las trayectorias vitales de Buenaventura Luna y Martín Castro existe dentro del libro para aportar a este argumento. Aunque, especialmente en el caso del segundo, el autor se cuida de remarcar que no fue "típico ni mucho menos representativo del criollismo popular de estos años [de entreguerra]" (p. 115).

Mucho más interesante resulta el segundo punto mencionado ya que, sin explicitarlo y con cierta timidez, de seguro tensionado por el marco teórico, le otorga peso al consumo como acción en las disputas culturales (y hasta políticas). Esto es lo que se está afirmando al sugerir que por "vía del consumo, el público que compraba folletos baratos guio las decisiones de los autores, de modo que la literatura criollista conservó, o incluso acentuó, los aspectos más disruptivos de los relatos de gauchos rebeldes" (p. 193). Si lo que "terminó forzando a las élites nacionalistas y al Estado" a aceptar al gaucho "como emblema de la nación” fue el "peso insoslayable que le dio el público popular a las historias de matreros", entonces uno de los campos de acción mediante el cual "el mundo popular hizo un aporte decisivo" fue el mercado de bienes culturales (p. 194), en el que votó con los bolsillos. Una proposición ciertamente novedosa ante la mirada peyorativa, y cuando no, ninguneo sistemático, que las humanidades y las ciencias sociales argentinas han reservado tradicionalmente para la cultura masiva y sus objetos. (De ello, el tan citado rescate de Robert Lehmann-Nitsche de la "Biblioteca Criolla" no es más que un ejemplo entre muchos).

Esta lectura, solapada a lo largo de todo el ensayo, informa también la interpretación de la decadencia del criollismo dentro del panorama cultural argentino. Pues, como el mismo autor señala, los cincuenta trajeron tanto la "emergencia de una cultura de masas ahora específicamente orientada a los sectores medios", como "la irrupción de una cultura juvenil de referencias trasnacionales", que desbancaron al gaucho con "íconos de rebeldía" que resultaban más atractivos para los consumidores de la segunda posguerra (p. 203). Así como Jauretche se vio profundamente impresionado por esos "Robin Hood paisanos" que protagonizaban "los dramas gauchescos" montados en "el pueblo bonaerense en que creció" (p. 198), niños y niñas nacidos en el siglo XX encontrarían otros "emblemas nacionales” más acordes a la era de la energía nuclear, la carrera espacial y la televisión, desde Diego Armando Maradona a Homero Simpson. Sin embargo, Adamovsky cierra el libro confirmando que aquel gaucho rebelde pervive hasta hoy, tanto en los esfuerzos oficiales de un Estado un poco fuera de sintonía, como en la religiosidad popular de un Gauchito Gil, como evidencia de la potencia del que supo ser el primer fenómeno de la cultura de masas en la Argentina. 